\title{
Living with children who have coeliac disease: a parental perspective
}

\author{
A-C Cederborg, Elin Hultman and Karin Fälth-Magnusson
}

\section{Linköping University Post Print}

N.B.: When citing this work, cite the original article.

This is the authors' version of the following article:

A-C Cederborg, Elin Hultman and Karin Fälth-Magnusson, Living with children who have coeliac disease: a parental perspective, 2012, Child Care Health and Development, (38), 4, 484-489.

which has been published in final form at:

http://dx.doi.org/10.1111/j.1365-2214.2011.01273.x

Copyright: Blackwell Publishing

http://www.blackwellpublishing.com/

Postprint available at: Linköping University Electronic Press

http://urn.kb.se/resolve?urn=urn:nbn:se:liu:diva-78804 


\section{Living with Children who have Celiac Disease: A Parental Perspective}

\section{Ann-Christin Cederborg*, Elin Hultman** \& Karin Fälht Magnusson***}

*Professor at the Department of Child and Youth Studies

Stockholm University

10691 Stockholm

Sweden

Email; ann-christin.cederborg@buv.su.se

**Doctoral student at the Department of Behavioural Sciences and Learning

Linköping University

58183 Linköping

Sweden

Email; elin.hultman@liu.se

*** Professor at Division of Pediatrics, Department of Clinical and Experimental Medicine, Faculty of Health Sciences, Linköping University,

58185 Linköping

Sweden

Email; karin.fahlt-magnusson@liu.se

Corresponding author:

Ann-Christin Cederborg

Department of Child and Youth studies, Stockholm university, 10691 Stockholm, Sweden.

Email: ann-christin.cederborg@buv.su.se

\section{Acknowledgment}

The authors are grateful to the The Swedish Society for Coeliacs, FORSS and the Swedish Research Council, who financially supported this study, but most of all to the families who so generously responded to the questions in this study.

Keywords: Children, Celiac Disease, Parental Perspective, Adaption process, 


\begin{abstract}
Background: This study explores how a child's celiac disease (CD) influences the daily life of families because such knowledge can enhance the understanding of how to support family adjustment to a gluten-free diet (GFD).

Method: We used an interpretative phenomenological approach (IPA), openly interviewing 20 parents of 14 children diagnosed with celiac disease about their individual thoughts and beliefs.
\end{abstract}

Results: Once parents know, especially when their children are young, they seem to have the capacity to rapidly adapt to GFD, mainly because they notice how quickly their children recover. Parents may have problems controlling how staff at day-care and at school complies with their information about a GFD.

Conclusions: To ensure that children with CD are given a GFD at daycare and school, it is necessary for municipalities to educate staff about the disease and to give them the prerequisites for serving a GFD. There is also a need of early identification of children who may have CD. When parents express their worries, not just at the hospital but also at the wellbaby clinic and primary care units, supporting treatment could prevent children from suffering from inappropriate food. 


\section{Introduction}

A child with health-related problems affects the dynamics of the family system (author, 1994), and the responsibility of daily care falls mostly on the adults, even if all family members have to adjust to the new circumstances. To our knowledge, no previous study exists in which parents have been interviewed about how they adapted to their children's need of a gluten free diet (GFD). In this study we therefore explore how a child's celiac disease (CD) influences the daily life of families. More specifically, we want to understand how parents perceive the adjustment process. We ask what strategies parents utilized when trying to lead a family life with a GFD. How they gained more knowledge about the disease and their attitude toward their children's special needs and their experience of knowledge and attitudes in their social surroundings in respect of their children's special needs.

\section{Materials and methods}

An interpretative phenomenological approach (IPA) was applied. The method is based on the assumption that participants' accounts of a certain phenomenon can give an individual perspective on thoughts and beliefs in relation to previous experiences (Dean et al., 2005; Smith, 1997; Willig 2009).

In total, we interviewed 20 parents of 14 children. Three groups of parents were involved in the interviews. The first group included parents whose children had gone through their first small intestinal biopsy (SIB) before two years of age (7 children and 13 parents). At the time of the interview, their children were between 3 and 5 years of age $(M=4.3$ years). Six of the children are girls and one is a boy.

The second group involved parents whose children were more than 12 years old when they went through their first SIB (3 parents of 3 children). The children were all girls between 16-17 years old $(M=16.3)$ when we interviewed their mothers. 
The third group consisted of parents whose children went through their first SIB when they were younger than two years of age but were almost at the same age as the children in the second group ( 4 parents of 4 children). Three of the children are girls and one is a boy. All of them were 16 years old when we interviewed their parents ( 1 father and 3 mothers).

The Ethical Committee at Linköping University approved this study (permit number M59-05).

\section{Data collection}

The inclusion criteria were that the children had a definite diagnosis of CD and had been living with the disease and a GFD for at least two years. Among those who met the inclusion criteria we consecutively chose 15 families with a child diagnosed with $\mathrm{CD}$. All but one of the selected representatives consented to being interviewed.

\section{Interview procedures}

The interviews took place in the participants' homes. We tape-recorded all the interviews and used a semi-structured interview guide that includes open-ended questions about how the parents experienced their children's disease. Depending on the parents' answers, we asked follow-up questions to obtain a deeper understanding of their experiences.

\section{Analysis}

The interviews were transcribed verbatim and exhaustively examined for references to similarities and differences. We then identified sections of the text that illustrate how parents experience their children's disease before and after diagnosis and how they manage to adapt to a GFD. Then we chose among the examples to find those that most obviously captured the participants' thoughts and beliefs.

\section{Results}


We organized the results under two categories with sub-themes; 1) the struggle to understand their children's disease before the diagnosis, and 2) the process of transforming to a GFD.

\section{The struggle to understand their children's disease}

Most of the parents believe that something is wrong with their child long before they receive the diagnosis.

\section{Suspicion before the diagnosis}

The mother of a five-year-old boy suspected something was wrong with her son when she tried to give him ordinary food.

Mother: In the beginning it went well, but when we started with ordinary food he just cried. It was a hard time because he bawled throughout the meals.

In a family with a five -year-old girl the child had lost weight alarmingly. In the hope of finding out what their child reacted to, the parents use "trial and error" to test different foods.

Father: She lost more than a kilo so she was really weak. It was terrible. Because it was connected to when she had ice cream and milk we started with lactose-free ice cream and oat milk. Then it was better, she did not vomit as frequently as before. So we felt it was something to do with milk.

Only one parent did not suspect that anything was wrong with her child. Her 17-year-old daughter had no symptoms before she, by coincidence, was tested at the age of 16 years.

Mother: She never showed any symptoms, she had never been sick. It was just by chance that she was tested. Then we found that she actually had CD.

\section{Diversity of understanding among professionals before diagnosis}


The parents described the process of gaining understanding among health-care professionals before the diagnosis as a "struggle". The parents consider that their concerns were not taken sufficiently seriously.

The mother of a four-year-old girl said that she suspected something was wrong with her daughter almost five months before the diagnosis was made. The staff at the wellbaby clinic told her not to worry.

Mother: Early on I felt that everything was not as it should be. They went against me many months before the diagnosis was made. Now looking back, I regret I did not stand my ground more than I did or go to a private doctor. Then she could have been diagnosed earlier or received help.

A mother of a five-year-old boy said that the staff at the well-baby clinic did not take her concerns seriously and the boy lost a lot of weight. When she turned to the primary care unit the doctor assessed her son as emaciated and immediately referred him to the hospital for an investigation.

Mother: Sure, children go through periods, as they said at the well-baby clinic, but this was strange. They thought for the most part that I was a nagging mother who came every week and whose son lost weight. I gave up in the end and went to the primary care unit. There they thought he was dehydrated, so we were referred to the hospital and we went there directly.

A mother of a 16-year-old girl went to the primary care unit and told the staff about her worries when her child was about two years of age. The staff was unpleasant and questioned her concerns. Finally, when one of the doctors investigated the girl she was sent to the hospital for an investigation.

Mother: She had been sick for a long time. I had been at the primary care unit many times, twice a week, and told them that her stomach was very swollen. An each time they said they were not responsible for that. Finally, we met a doctor who looked at her, and he immediately sent her to the hospital. At the time she was in a very bad condition. She was undernourished. 


\section{Reactions after diagnosis}

Most of the parents said that they were relieved when they knew what was wrong with their child. A mother of a four-year-old girl said:

Mother: It was wonderful to get the diagnosis. It was a relief because then we knew that there was something, we knew that our suspicions were right.

A mother of 16 -year-old girl said that the diagnosis explained her daughter's previous tiredness.

Mother: She was often very tired before she was diagnosed, and we did not know why. The diagnosis explained the reason for her tiredness.

Getting the diagnosis meant that parents knew how they could help their child to reduce symptoms. The parents of a three-year-old girl said that they noticed a change in their daughter's behavior as soon as she started a GFD.

Mother: We noticed the change after a couple of days, she became a different child.

Father: First it was her temperament, then we saw how her body changed. She had a very swollen stomach compared with the rest of her body, where she was very thin. That was the most pleasant feeling, when we saw the difference. Now she is much better.

\section{Transforming to a GFD}

After the diagnosis was made the parents had to change their food habits. Most of them reported a rapid normalization process to a GFD. A mother of a three-year-old girl said that after diagnosis, she was confused for about two months.

Mother: The first month I panicked about everything. I questioned whether I could be outdoors with my child during the harvest, was she going to be allergic? The 
first two months were a mess that was before we were able to get started. It was the whole business of shopping. Usually we just took what we wanted, but now we had to read the contents before we could buy any food.

The mother of another three-year-old girl said that the dishes were mostly the same after the diagnosis.

Mother: We do not eat differently compared with what we did before the diagnosis. We have just changed small things. Now we know what products are free of gluten, which almost all are. The only thing that is different from before is the pasta.

Parents also express their appreciation of their children's response to a GFD. According to a mother of a four-year-old the daughter seems to know what she can eat or not.

Mother: As she is getting older she becomes more and more aware of this. I can see that she think it is bit boring at times if she cannot eat something. She never speaks about it, but avoiding food with gluten is all she knows.

A mother of a 17-year-old girl, who received her diagnosis when she was a teenager, says, however, that her daughter had a hard adaption process to the GFD.

Mother: It might be different if she got sick as soon she ate gluten food. Then you know you cannot eat this because you will get sick and will not feel well afterwards.

Parents whose children were diagnosed when they were young have had the opportunity to socialize their children into a GFD. Their children had usually not experienced the taste of gluten food and were not aware of what they were missing. The mother of a five-year-old boy expresses her happiness about his positive responses to the GFD.

Mother: He does not question it if he cannot eat what is served. He asks first "Can't I have that?" and gets a "No, you can't", and he is happy with that. He is very much aware, he is so good. 


\section{Implications for everyday life}

Even if most of the parents soon after diagnosis adapted to the GFD, their everyday life was altered because of the child's needs. A mother of a five-year-old girl could not stop worrying about what would happen if her daughter tasted something she should not eat.

Mother: It is always there that she should not get access to crumbs. I carefully wipe off the table and the floor so that she cannot get anything in her mouth when she crawls around. At times I worry when she is tired and is whining. She had a lot of rashes before Christmas and she had fever, and then I wondered if she had eczema or psoriasis because of her CD.

\section{Fewer visits to restaurants}

Most of the parents reported that they seldom visited restaurants for reasons such as not trusting the staff's description of the ingredients or the lack of food adapted to their children's needs. The mother of a 16-year-old girl does not eat out because she wants to avoid her daughter's worries about the content of the food.

Mother: We do not go to restaurants very often because I feel sorry for her. She is afraid to become ill. So you don't eat out, and say that you will do it later on.

\section{Limited leisure-time activities}

The mother of a 16-year-old boy said that CD influences the social life of her son.

Mother: It is much more than the restricted food that influences him. He cannot spontaneously be with his peers, everything has to be checked and questioned if he eats with them. I think that he is afraid that his peers will think he is a bother to be with. I think the disease hinders him socially.

\section{Limited traveling}


Parents also said that traveling abroad could be demanding because of difficulties getting access to proper food. A mother of a 16-year-old boy diagnosed when he was very young was afraid that that he could become seriously ill if he had gluten food.

Mother: We are doubtful about traveling because he is very sensitive. His problem has slowed us done a bit.

\section{Controlling or trusting others}

Family and friends

Parents reported being met with sympathy for the most part when they told family and friends about their children's disease. In a family with a five-year-old girl the mother wants, however, to be in control of what kind of food her friends serve her child.

Mother: When we are going to visit people I phone them before and ask about the food. Even if I have told everyone that she has CD, I cannot be sure what they understand. There have been mistakes and I cannot expect other people to understand. That is why I have to check them.

A father of a three-year-old girl resolved his concerns about food intake in the following way:

Father: It is not a problem because I think for my friends. We give them our ingredients or they buy gluten-free food themselves. They always have gluten-free food when we visit them.

The mother of a 16-year-old girl thinks that her family is fortunate because they not have to consider whether or not their child was going to be served proper food when visiting others.

Mother: They know how to make food that is free from gluten. They call us and ask if they have any questions. We know that the food they serve is free from gluten.

Daycare and school 
The struggle to get staff at daycare and school to understand their children's need of a GFD can be demanding for parents. A mother of a five-year-old girl believes that daycare staff is not sufficiently educated about how to understand CD.

Mother: It is a bit sad that she might not get certain food because they do not know about the disease. I have given them written information about gluten because I wanted them to know what it is.

Parents also talked about negative attitudes from staff at the schools' dining hall. The mother of a 17-year-old girl said she was unhappy because her daughter experiences that food at school is not adapted to her needs.

Mother: When serving children food at high school, the staff should be aware of what it means to be lactose intolerant and have $\mathrm{CD}$, but she does not get food that is adapted to her condition. She frequently has to tell the staff what type of food they should give her. This drives me crazy.

\section{Buying gluten-free food}

Even if parents mostly buy subsidized food from the pharmacy, they supplement their purchases with gluten-free food from grocery stores. A mother of a five-year-old girl explained that she constantly reads the contents when she buys groceries from stores.

Mother: In some grocery stores they have all the gluten-free food in one place. In others it is all over the store and then you have to run round and look for it. This means you have to check the contents on every packet.

The father of a three-year-old girl expressed his satisfaction with the grocery stores because they increased their assortment continuously in order to satisfy people with CD. 
Father: During the short time we have known about the diagnosis, the grocery stores have increased their assortment of gluten-free food. In the beginning we really had to search for that type of food.

\section{Information-seeking process}

Regardless of previous knowledge about the disease the parents actively and constantly try to find out as much as possible about how to meet their child's GFD needs. In one family the parents of a four-year-old girl find new research results, which they wish they could discuss more often with their pediatric specialist.

Mother: I have read a lot about the disease so I have background knowledge. I have found some interesting things from other countries that I very much would like to discuss, but it can be hard to find experts that can explain how to understand these findings..

The parents of a three-year-old girl search for knowledge through people who know about the disease, on the Internet, and through the CD association.

Mother: In order to receive tips and ideas I read about it on the Internet, I am a member of the celiac association and discuss it with people in our surroundings. You cannot get any tips from ordinary newspapers. If you have the disease, you look for information, and it is possible to find good information.

Most of the parents have regular contact with a dietician. The mother of a 16-year-old girl who received the diagnosis when the girl was 14 years old is very happy with the information she received from the staff at the hospital.

Mother: Since we received the diagnosis we have been given good information. I just call the hospital and talk to a dietician. It is not hard at all.

\section{Concerns about their children's future}


The involved parents reported that they also have to cope with concerns about their children's future. A mother of a five -year-old girl said that she is worried about how her daughter will manage her life when she is living by herself.

Mother: This is a lifelong disease. Perhaps I will help her out when she is old enough to leave home. I feel sorry for her, but I try to think that others might have an even worse situation.

Parents put their hope on new treatment based on scientific breakthroughs. The mother of a 16- year-old girl spoke of a tablet that could be taken instead of eating a GFD.

Mother: I know they have a tablet that can be used. I want her to be able to eat ordinary food.

Another mother of a 16-year-boy was concerned about how the disease could limit her son's opportunities to live an ordinary life.

Mother: It is the military service ... that he cannot do it. Deep down I am a bit worried. I sincerely hope that the disease is not going to affect his coming life and be a hindrance to him. I want him to have a normal life.

\section{Conclusion}

In this study we found that most of the interviewed parents' complied with the GFD as soon as they received the diagnosis. Confirmation of suspected symptoms and advice about how to feed their children facilitated the adaption process, especially because they saw that their children almost immediately felt better and gained weight with food that was free of gluten. It may be easier to adapt to a GFD if the children are young when diagnosed because then they learn early in life what food they tolerate, and they have limited experience of how a diet that contains gluten can taste. Parents whose children are diagnosed in their teens can find it more difficult to comply with a GFD, especially when their teenagers do not 
have symptoms when eating food containing gluten. This may be because their children know what type of food they have to give up, which can be food they really like. Adolescents appreciate, however, the way their family support their needs to follow a GFD (Olsson et al., 2008).

All the parents but one said they were concerned about their children's symptoms before diagnosis. They could not understand what was wrong with their children. Those who expressed their concerns at the well-baby clinic said that the staff did not understand them, dismissed their concerns and assessed them as overly anxious. Experiences of being understood at the primary care clinics varied, but obstinacy resulted in a referral to the hospital. Unfortunately, most of the children had lost a lot of weight before such a referral. Once the doctors showed that they understood them and informed them about $\mathrm{CD}$, the parents were relieved, not least because they learned how to help their children.

Regardless of when the diagnosis was made, the parents do worry about their children's food intake when they are not at home. To prevent the children from eating the wrong food they spend time and effort to inform relatives, friends, daycare and schools about the need of GFD. The most complicated situation is when they visit restaurants in Sweden and abroad. The selection of GFDs is limited, and it is hard for them to influence the content of the food.

The parents seek information about the disease and suitable ingredients. The Internet is one source of information; another is an association for people with $\mathrm{CD}$. They also appreciate the advice they receive from dieticians at the hospitals.

The parents interviewed can be described as engaged parents who took their children's need of a GFD seriously. This is necessary to make the everyday life of these children as normal as possible (Jackson et al., 1985; Anson et al 1990). Parent cannot prevent their children from feeling different from others at times. If, however, parents are able to 
teach their children how to cope with the disease, they may be socialized into an understanding of how to prevent food intake they cannot tolerate.

Parents may have problems controlling how staff at day-care and at school complies with their information about a GFD. To ensure that children with CD are given a GFD at daycare and school, it is necessary for municipalities to educate staff about the disease and to give them the prerequisites for serving a GFD.

The study has shown us the importance of identifying at an early stage children who may require a GFD. We believe, therefore, that if staff at well baby clinics and primary care units were more understanding when parents express their concern, it might result in earlier referral to a hospital and earlier identification of the disease. Parents seem to have the capacity to rapidly adapt to the GFD, primarily because they immediately notice how their children recover.

\section{Key message:}

- Once parents know about the diagnosis, especially when their children are young, they seem to have the capacity to rapidly adapt to GFD.

- It is necessary for municipalities to educate staff about the disease and to give them the prerequisites for serving a GFD.

- When parents express their worries, supporting health care treatment could prevent children from suffering from inappropriate food. 


\section{References:}

Anson, O., Weizman, Z., \& Zeevi, N. (1990). Celiac disease: Parental knowledge and attitudes of dietary compliance. Pediatrics, 85, 98-103.

Author. (1994).

Dean, S.G., Smith, J.A., Payne, S. \& Weinman, J. (2005) Managing time: An interpretative analysis of patients' and physiotherapists' perceptions of adherence to therapeutic exercise for low back pain. Disability and Rehabilitation, 27(11), pp 625-636.

Jackson, P. T., Glasgow, J. F. \& Thorn, R. (1985). Parents' understanding of coeliac disease and diet. Archives of Disease in Childhood, 60, 672-674.

Olsson, C., Hörnell, A., Ivarsson, A. \& Sydner, Y.M. (2008). The everyday life of adolescent coeliacs: issues of importance for compliance with the gluten-free diet. Journal of Human Nutrition and Dietetics, 21, 359-367.

Smith, J. A. (1997) Developing theory from case studies: Self reconstruction and the transition to motherhood. In N. Hayes (ed) Doing qualitative analysis in psychology. (Hove: Psychology Press).

Willig, C. (2006) Introducing qualitative research in psychology. Adventures in theory and method. (New York: Open University Press). 